\title{
DESCORTESÍA INVOLUNTARIA EN EL ESPAÑOL HABLADO POR INMIGRANTES SINOHABLANTES RESIDENTES EN MADRID: ANÁLISIS DE LOS RASGOS MELÓDICOS
}

\author{
Cristina Herrero Fernández
Universidad Nebrija, España \\ Cristina Herrero Fernández
Universidad Nebrija, España \\ cherrerof@nebrija.es \\ https: / / orcid.org/0000-0001-9842-532X
}

Susana Martín Leralta

Universidad Nebrija, España

smartinl@nebrija.es

https: / /orcid.org/0000-0002-1816-1967

\author{
Margarita Planelles Almeida \\ Universidad Nebrija, España \\ mplanelles@nebrija.es \\ https: / / orcid.org/0000-0002-7066-0165
}

Recibido:05/05/2021 | Aceptado: 10/12/2021

Cita recomendada:

Herrero, C.; Planelles, M.; y Martín, S. (2021). Descortesía involuntaria en el español hablado por inmigrantes sinohablantes residentes en Madrid: análisis de los rasgos melódicos. Phonica, 17, 50-71. https://doi.org/10.1344/phonica.2021.17.50-71

\section{Resumen}

En el presente trabajo se describen las características melódicas de enunciados realizados con intención cortés por inmigrantes sinohablantes residentes en la Comunidad de Madrid, pero percibidos como descorteses por hablantes de español L1. Para ello, en primer lugar, se elicitó un corpus de peticiones realizadas con intención cortés por 20 hablantes de mandarín L1 en español L2. En segundo lugar, se realizó un test de percepción del grado de cortesía de los enunciados con 92 jueces hablantes de español L1 residentes en la Comunidad de Madrid. En último lugar, se analizaron los rasgos melódicos de las peticiones percibidas como descorteses utilizando el método del Análisis Melódico del Habla (Cantero y Font-Rotchés, 2009, 2020). Finalmente, se observó que los enunciados percibidos como claramente descorteses contenían varios rasgos melódicos de descortesía en español descritos en Devís (2011) y se hipotetizó que estos rasgos podrían ser, al menos en parte, responsables de la percepción de la descortesía involuntaria.

Palabras clave: Rasgos melódicos; Descortesía involuntaria; Sinohablantes; Español L2. 


\title{
Descortesia involuntària a l'espanyol parlat per immigrants sinohablants residents a Madrid: anàlisi dels trets melòdics
}

Resum: En aquest treball, es descriuen les característiques melòdiques d'enunciats realitzats amb intenció cortesa per immigrants sinoparlants residents a la Comunitat de Madrid, però percebuts com a descortesos per parlants d'espanyol L1. Per això, en primer lloc, es va elaborar un corpus de peticions realitzades amb intenció cortesa per 20 parlants de mandarí L1 en espanyol L2. En segon lloc, es va realitzar un test de percepció sobre el grau de cortesia dels enunciats amb 92 jutges parlants d'espanyol L1 residents a la Comunitat de Madrid. En darrer lloc, es van analitzar els trets melòdics de les peticions percebudes com a descorteses utilitzant el mètode Anàlisi Melòdica de la Parla (Cantero $\mathrm{i}$ Font-Rotchés, 2009, 2020). Finalment, es va observar que els enunciats percebuts com a descortesos contenien diversos trets melòdics de descortesia en espanyol descrits a Devís (2011) i la hipòtesi és que aquests trets podrien ser, almenys en part, responsables de la percepció de la descortesia involuntària.

Paraules clau: Trets melòdics; Descortesia involuntària; Sinoparlants; Espanyol L2.

\section{Unintentional impoliteness in Spanish spoken by Chinese immigrants living in Madrid: analysis of melodic features}

\begin{abstract}
The present work describes the melodic characteristics of intentionally polite requests made in L2 Spanish by L1 Chinese speakers living in Madrid, which are perceived as impolite by L1 Spanish speakers. First, a corpus of intentionally polite requests was built by recording 20 speakers of Mandarin L1 in Spanish L2. A perception test of the degree of politeness of the statements was then carried out by 92 L1 Spanish-speaking raters living in Madrid. Subsequently, the melodic features of the requests perceived as impolite were analysed using the Melodic Analysis of Speech method (Cantero and FontRotchés, 2009, 2020). We have observed that sentences perceived as clearly impolite contained several melodic characteristics of impoliteness in Spanish as described by Devis (2011) and it was hypothesised that these traits could be, at least in part, responsible for the perception of unintentional impoliteness.
\end{abstract}

Keywords: Melodic features; Unintentional impoliteness; Chinese speakers; L2 Spanish. 


\section{Introducción}

El dominio de las estrategias de fonocortesía es clave a la hora de evitar conflictos en situaciones de comunicación intercultural. Sin embargo, el desarrollo de la competencia pragmática es particularmente complejo para hablantes de lenguas extranjeras, especialmente cuando las estrategias prosódicas utilizadas en la L2 para expresar cortesía difieren de las utilizadas en la L1. No obstante, si bien el desarrollo de la competencia pragmática suele estar presente entre los objetivos de los programas de aprendizaje de lenguas extranjeras, el desarrollo de la competencia fonopragmática $\mathrm{y}$, en concreto, la adquisición de la entonación de (des)cortesía sigue siendo un gran olvidado, a pesar de haberse observado que el uso de la entonación puede ser clave en la integración y la inclusión de los inmigrantes, tanto a nivel social como profesional (Bednarz, 2017; Machetti y Rocca, 2017), dado que errores en la producción de la entonación de (des)cortesía pueden derivar en exclusión de los inmigrantes en el terreno laboral (GrünhageMonetti y Svet; 2017: 319).

Estudios recientes (Devís, 2011) han arrojado luz sobre el efecto de la entonación en la percepción de la (des)cortesía en español al comprobar de manera empírica que, en esta lengua, los rasgos melódicos son, por sí solos, capaces de transformar un acto de habla extremadamente cortés en uno extremadamente descortés. Como sabemos, el español es una lengua entonativa en la que la entonación de cortesía ha sido estudiada en profundidad (Quilis, 1993; Haverkate, 1994; Hidalgo, 2001, 2006, 2007, 2009; Waltereit, 2005; Álvarez y Blondet, 2003; Briz e Hidalgo, 2008; Devís, 2011). Diferente es el caso del chino mandarín, lengua tonal en la que la compleja interacción de tono y entonación aún no ha sido descifrada en su totalidad (Xu, 2015). Por lo tanto, conocer en mayor profundidad las características melódicas de la (des)cortesía en chino mandarín L1 y en el español hablado por sinohablantes es clave para poder descubrir las posibles dificultades que pueden encontrar a la hora de expresar mensajes con el grado de cortesía deseado, y evitar así situaciones de descortesía involuntaria que puedan derivar en malentendidos lingüísticos, dado que, como sabemos, parece existir una tendencia a transferir los hábitos entonativos de la lengua materna de manera automática (Cortés, 1999). Así se ha comprobado en numerosos estudios de la entonación del español hablado por sinohablantes (Cortés, 1997, 1999, 2002, 2004, 2005; Liu, 2005), en los que se ha observado que fenómenos característicos de la interlengua fónica de este grupo de hablantes, como la inestabilidad tonal inter- e intrasilábica (Liu, 2005), pueden no solo hacer que se perciba un claro acento extranjero, sino que este dificulte considerablemente la comprensibilidad de los mensajes y, por tanto, de los ciudadanos sinohablantes en español L2.

Si bien el efecto de la transferencia de los rasgos melódicos de los hablantes sinohablantes ha sido estudiado y descrito (Cortés, 2004, 2005; Liu, 2005) tanto en el nivel lingüístico, es decir, aquel que permite la diferenciación de las modalidades oracionales, como en el nivel prelingüístico o aquel que se refiere a la organización del discurso y en el que se identifica, por tanto, el acento extranjero, aún son necesarios estudios que arrojen luz sobre el posible efecto pragmático de dicha transferencia de rasgos melódicos en el nivel paralingüístico de la entonación. El objetivo de este trabajo es, por tanto, observar este fenómeno y llevar a cabo, así, un diagnóstico de las posibles causas de la inadecuación fonopragmática de sinohablantes en español L2. Para ello, nos centramos en este trabajo en la petición, uno de los actos de habla corteses a los que los hablantes recurrimos con mayor frecuencia, tanto en el ámbito público como en el privado. En muchas ocasiones, de cómo se exprese lingüísticamente la petición dependerá que se logre o no el objetivo del hablante, dado que para conseguir con éxito la meta comunicativa, este debe hacer uso de determinadas estrategias de atenuación (Briz, 2004; Briz y Albelda, 2013). Sin embargo, en muchas ocasiones, los hablantes de lenguas extranjeras desconocen dichas estrategias, incluso en los niveles más avanzados de aprendizaje de la lengua. El hablante de lenguas extranjeras, ante una situación de malentendido intercultural, tiende a considerar que la causa de la inadecuación pragmática se puede encontrar en la escasez de recursos a nivel léxico-gramatical, pero en pocas ocasiones será consciente de que la posible causa se puede encontrar en el nivel fónico. Sin embargo, como ya hemos mencionado, en algunas lenguas entonativas como el español, los 
rasgos melódicos son capaces de, por sí solos, convertir un enunciado descortés, como es la orden, en uno cortés, como es la petición (Devís, 2011), lo que nos lleva a pensar, en la línea de autores como Astruc y Vanrell (2016), que el dominio de la entonación de cortesía en el caso de hablantes de español L2 podría ser clave para ayudar a transmitir la cortesía e, incluso, en los niveles más bajos de competencia lingüística, ayudar a compensar la falta de recursos léxico-gramaticales necesarios para una correcta adecuación pragmática en cualquier situación. Como indica Roldán, "cuando la entonación se presenta como recurso único de atenuación en un enunciado, su presencia suple la falta de otros atenuadores" (2000: 118).

\section{Rasgos melódicos de cortesía en español}

En español, la cortesía a nivel suprasegmental corresponde, principalmente, a la entonación (Quilis, 1988, 1993; Hidalgo, 2001, 2006, 2007, 2009; Waltereit, 2005; Haverkate, 1994; Álvarez y Blondet, 2003; Briz e Hidalgo, 2008; Devís, 2011). Partimos, para poder hablar de entonación de cortesía, de la idea de que, si bien la entonación lingüística constituye un código, la entonación paralingüística, que incluye la entonación de cortesía, está formada por códigos semiestables (Devís, 2011) que hacen que se comprenda la intención cortés o descortés del hablante, dado que los rasgos melódicos que caracterizan la entonación de cortesía no pueden ser idiosincrásicos y depender de cada individuo, sino que deben ser compartidos por una comunidad (Cantero, 2014: 622). Ya en 1944, Navarro Tomás observó que existía una diferencia a nivel melódico entre la petición y la orden. Para el autor, los recursos gramaticales no eran suficientes para describir la realización en español de las que él denomina "modalidades de la expresión del deseo: invitación, recomendación, mandato, petición, ruego, súplica" (1944: 184). Para el autor, tanto ruego como súplica son consideradas peticiones, y se caracterizan a nivel melódico por tener sílabas tónicas altas con un descenso gradual y tonema de anticadencia, mientras que lo que él denomina mandatos se caracterizan a este nivel por tener una línea tonal elevada, un tonema de cadencia o circunflejo y un rango tonal más amplio. La principal diferencia entre ambos es, según el autor, el tono de juntura final, ascendente en las peticiones y descendente en las órdenes.

Quilis (1993), Haverkate (1994), Roldán (2000), Álvarez y Blondet (2003), Waltereit (2005) y Orozco (2008) también realizaron sus hipótesis sobre los rasgos melódicos concretos responsables de la percepción de cortesía en diferentes variedades del español. En el caso del español peninsular, la aportación más relevante, por su exhaustividad y por el rigor científico de la metodología, es el estudio de Devís (2011), quien llegó a la conclusión, después de transformar órdenes en ruegos a través de manipulaciones melódicas, de que los rasgos capaces de aportar atenuación por sí solos son las inflexiones internas, las prominencias en átonas y las inflexiones circunflejas, mientras que los rasgos que pueden atenuar los enunciados, en interacción con otros como las inflexiones internas y las prominencias en átonas, son las inflexiones finales interrogativas y las inflexiones finales suspensas. Por otro lado, encontró que el énfasis de palabra y la F0 baja no eran factores que por sí mismos fueran capaces de atenuar enunciados con algún tipo de "agresividad" léxico-gramatical. 


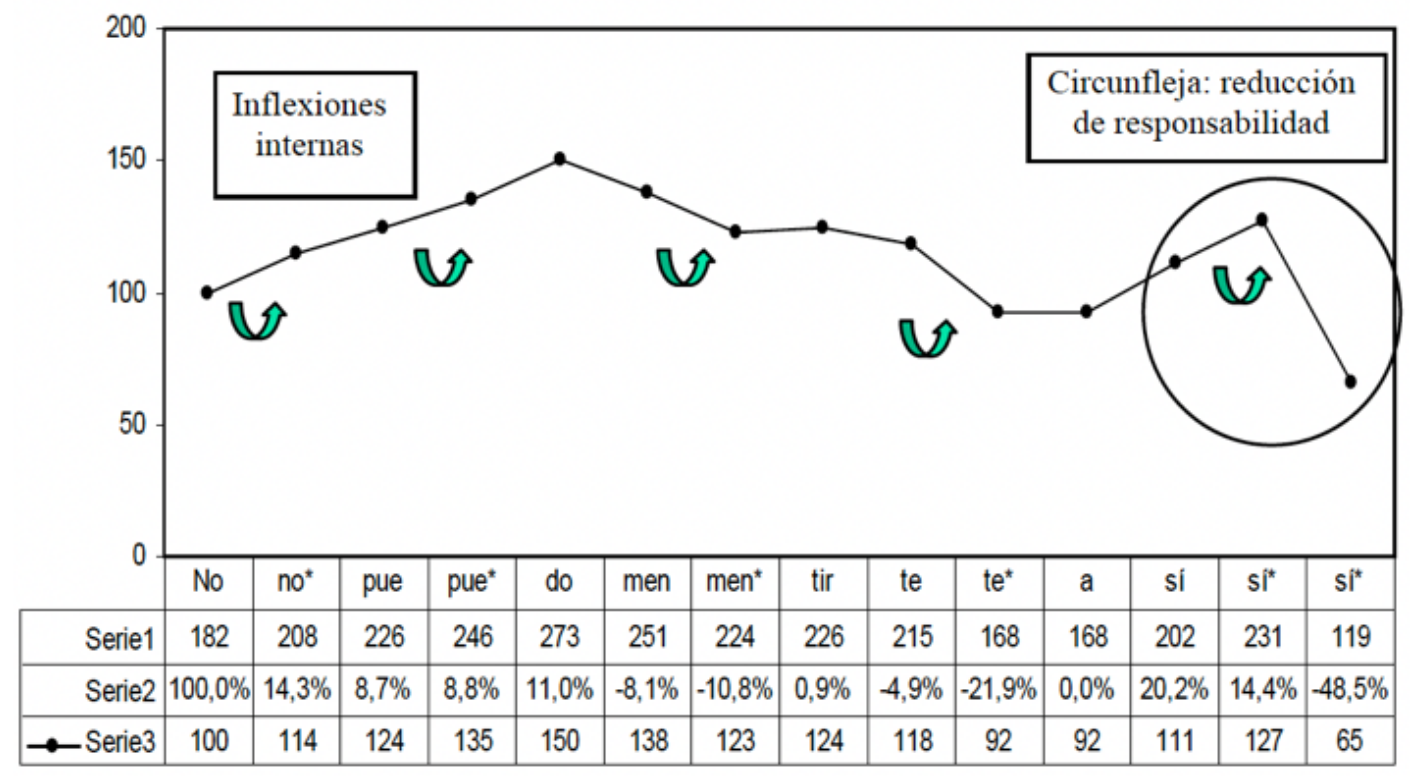

Figura 1. Rasgos melódicos de cortesía en español. (Devís, 2011)

En la figura 1 se puede observar el gráfico correspondiente al análisis melódico del habla de uno de los enunciados representativos de la atenuación cortés en español presentados por Devís (2011). En este se pueden apreciar los siguientes rasgos melódicos característicos de la cortesía en español: inflexiones internas, primer pico desplazado e inflexión final circunfleja (asc.-desc.).

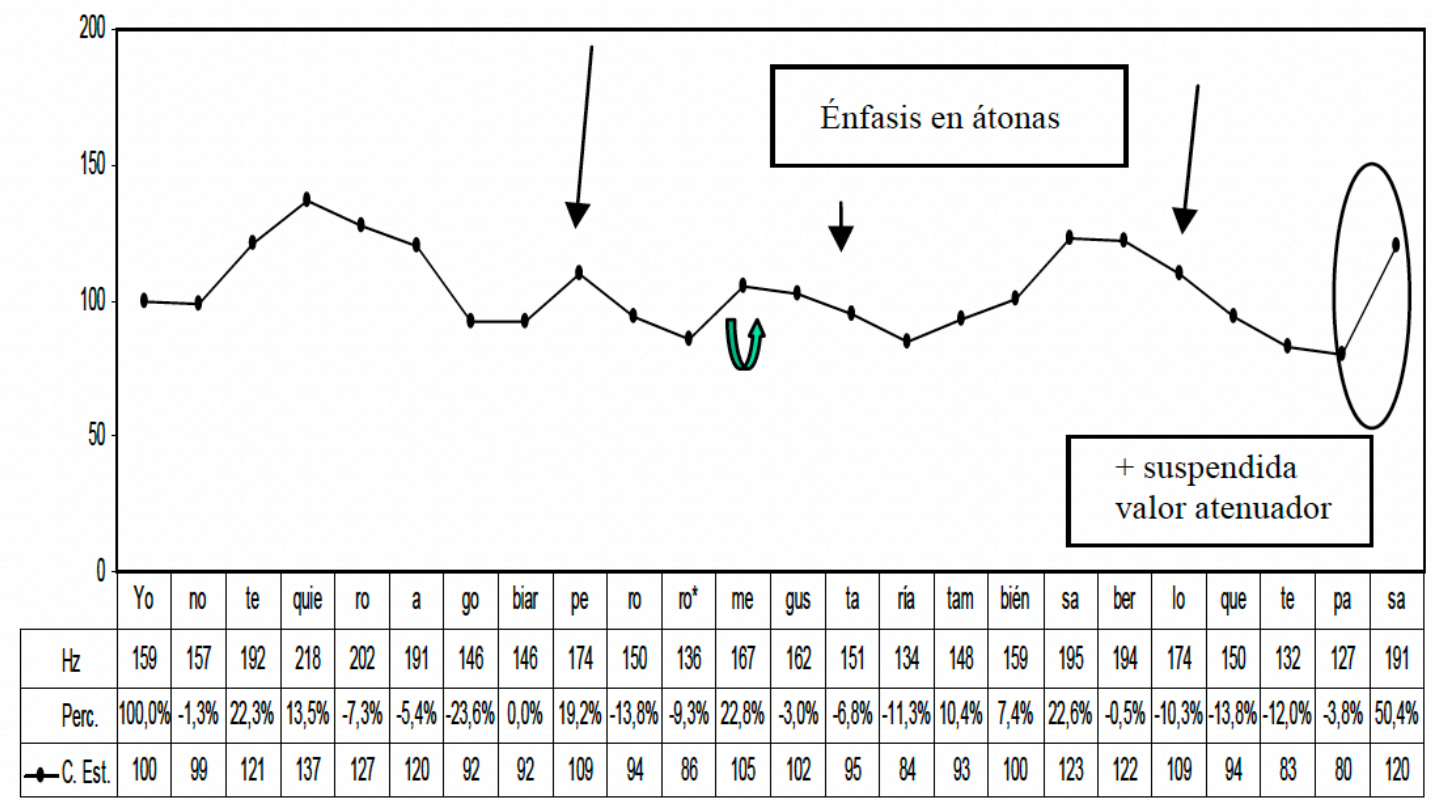

Figura 2. Rasgos melódicos de cortesía en español. (Devís, 2011)

En este segundo ejemplo (figura 2) proporcionado también por Devís (2011), se puede observar que el énfasis de foco ancho en vocales átonas y el final suspendido son mecanismos de atenuación cortés en español. 
Resumimos a continuación los rasgos melódicos de cortesía encontrados en Devís (2011):

\begin{tabular}{|c|}
\hline RASGOS MELÓDICOS DE CORTESÍA EN ESPAÑOL \\
\hline $\begin{array}{c}\text { Inflexión final }+ \text { suspendida: } \\
\text { (con ascenso final entre el } 15 \text { y el 70\%) }\end{array}$ \\
\hline Inflexión final + interrogativa \\
\hline Prominencia en átonas \\
\hline Inflexiones internas \\
\hline Registro tonal bajo \\
\hline Primer pico desplazado o ausente \\
\hline Énfasis de palabra con inflexión circunfleja \\
\hline Énfasis de palabra con inflexión \\
+ interrogativa \\
\hline
\end{tabular}

Tabla 1. Rasgos melódicos de cortesía en español. (Devís, 2011)

Posteriormente, se llegó a conclusiones similares sobre la entonación de cortesía del catalán, lo que conduce a concluir que puede que exista un código común a ambas lenguas y que sus hablantes quizás constituyan una comunidad cultural homogénea en este aspecto (Devís y Cantero, 2014).

\section{Rasgos melódicos de cortesía en chino}

El chino mandarín es una lengua tonal que podría recurrir a partículas y estructuras sintácticas para suplir algunas funciones que realiza la entonación de cortesía en lenguas entonativas como el español. En consecuencia, la mayor parte de los estudios sobre cortesía en chino se han centrado en el uso de estas partículas y no en los rasgos melódicos, más difíciles de analizar en una lengua tonal. Sin embargo, es importante resaltar que la entonación en chino es un fenómeno independiente del tono léxico, aunque el rasgo acústico de ambos sea la F0, y, como tal, tiene una función lingüística y otra expresiva o emocional. Shen (1990: 9), en esta línea, considera la entonación emocional y expresiva como un grado de entonación que se añade a la entonación lingüística y al tono léxico. Li, Fang y Dang (2011) propusieron, después de observar este fenómeno empíricamente y partiendo de la idea de que la entonación emocional se superpone a la entonación lingüística, una serie de etiquetas $(r, f, 1)$ para este tipo de entonación que se combinaría con las clásicas etiquetas de los tonos de frontera del sistema métrico autosegmental H\% y L\%. Chao (1933), uno de los primeros y más importantes entonólogos del chino, ya reflexionó sobre la entonación emocional o expresiva e hizo la misma diferenciación entre tono, entonación neutra y entonación expresiva, siendo la suma de los últimos dos elementos lo que conformaría la entonación. Según Chao (1933), gran parte del movimiento melódico en chino se debe a la actitud o la emoción del hablante. Así pues, la bibliografía sobre entonación expresiva en chino se divide entre aquella que se centra en la entonación emocional y aquella que se centra en la entonación actitudinal.

Chao (1933) sugirió que el tono añadido de frontera posterior al tono (successive addition boundary tone) se utiliza en chino para expresar emoción o actitud. Así, el enfado, por ejemplo, se expresaría con un tono añadido descendente, mientras que la alegría, en cambio, lo haría con un tono ascendente añadido al tono léxico. Chao (1933) lo representó gráficamente del siguiente modo: 


\begin{tabular}{|c|c|c|c|c|}
\hline After & Pitch & Graph & \multicolumn{2}{|c|}{ Example } \\
\hline lst Tone & $552:$ & 有盖 & Yeou jiang, & 'There's ginger, \\
\hline 2nd Tone & $352:$ & 有糖 & yeou tarng. & and sugar, \\
\hline 3rd Tone & 2141: & 有酒 & yeou jeou, & and wine, \\
\hline 4th Tone & 5121: & 有醋 & yeou tsuh. & and vinegar.' \\
\hline
\end{tabular}

Figura 3. Tonos descendentes añadidos posteriormente a los cuatro tonos. (Chao, 1933)

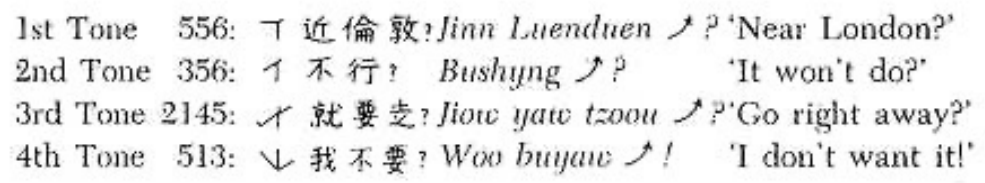

Figura 4. Tonos ascendentes añadidos posteriormente a los cuatro tonos. (Chao, 1933)

El término utilizado por los autores que siguen el modelo métrico autosegmental de análisis de la entonación para referirse a este fenómeno es "tono de frontera no léxico". Müller-Liu (2006) comprobó con un estudio perceptivo y de análisis acústico la existencia de estos tonos posteriores añadidos al tono léxico propuestos, a nivel teórico, por Chao (1933). A pesar del interés mostrado en la entonación emocional y actitudinal por parte de Chao (1933), gran parte de la bibliografía y los estudios sobre entonación posteriores se centraron en la entonación lingüística, dejando a un lado la entonación expresiva, ya que, como indica Müller-Liu (2006), durante los últimos años la investigación se ha centrado en analizar los movimientos melódicos que tienen un efecto en la modalidad de la oración o la estructura sintáctica de la misma, como confirman estudios recientes sobre la entonación en chino (Wang, Xu y Ding, 2018), centrados especialmente en el fenómeno de foco en esta lengua.

Asimismo, los estudios que se han centrado en los rasgos prosódicos de (des)cortesía en chino mandarín no han encontrado una correlación entre el parámetro de la F0 y la percepción de la descortesía. Fan y Gu (2016), después de analizar y manipular diferentes rasgos prosódicos y observar su efecto en la percepción de la descortesía, observaron que la velocidad de habla tenía un efecto más significativo en el juicio de cortesía que la F0 media y el rango de F0. Los investigadores observaron que al acelerar la velocidad del enunciado original el grado de percepción de la cortesía disminuía gradualmente, especialmente cuando el enunciado original era cortés, mientras que decelerar la velocidad del enunciado original apenas repercutía en el juicio de cortesía. Por otro lado, el rango tonal no pareció tener efecto en el juicio de cortesía, y la F0 media mostró tener un efecto muy limitado, solo capaz de neutralizar el habla (des)cortés levemente cuando la F0 era más baja que en el original. Esto, sin embargo, no es indicador de que los rasgos melódicos no sean relevantes a la hora de producir o percibir la (des)cortesía, dado que dichos parámetros analizados (rango de F0 o F0 media) no ofrecen información detallada sobre información representativa del fenómeno. Sin embargo, si tenemos en cuenta que el chino mandarín es una lengua tonal, podríamos hipotetizar que puede que, efectivamente, los rasgos melódicos no sean los rasgos prosódicos más relevantes a la hora de expresar y percibir cortesía en chino mandarín, como parece que sí podría ser en español. Esto, evidentemente, se podría traducir en una seria dificultad para los aprendientes sinohablantes de español L2 a la hora de intentar expresar la cortesía en esta lengua. En consecuencia, el presente estudio tiene por objetivo observar las características melódicas de los enunciados realizados con intención cortés por inmigrantes sinohablantes residentes en la Comunidad de Madrid y percibidos como descorteses por parte de hablantes de español L1. Como hablantes de una lengua tonal, consideramos que los sinohablantes podrían tener una dificultad añadida a la hora de expresar cortesía en español L2, aunque consideramos que la dificultad puede ser generalizada entre los aprendientes de lenguas extranjeras, especialmente aprendientes de lenguas entonativas caracterizadas por tener una clara entonación de cortesía, como es el caso del español. 


\section{Estudio empírico}

El objetivo de este estudio es analizar, desde el punto de vista melódico, el fenómeno de la (des)cortesía involuntaria de los trabajadores sinohablantes en la Comunidad de Madrid. Para ello, se planteó analizar los rasgos melódicos de las producciones realizadas con intención cortés en español L2 por parte de inmigrantes sinohablantes residentes en la Comunidad de Madrid y percibidas como descorteses por hablantes de español L1. En primer lugar, se realizó un test de percepción en el que hispanohablantes residentes en la Comunidad de Madrid evaluaron el grado de (des)cortesía de peticiones producidas con intención cortés por inmigrantes sinohablantes residentes en la Comunidad de Madrid. Posteriormente, el análisis melódico, realizado siguiendo el protocolo para el Análisis Melódico del Habla (Cantero, 2002; Cantero y Font-Rotchés, 2009, 2020), de aquellos enunciados percibidos como descorteses a pesar de la intención cortés de los informantes sinohablantes, arrojó luz sobre los rasgos melódicos concretos presentes en dichos enunciados.

\subsection{Objetivo y preguntas de investigación}

Este estudio tiene por objetivo observar los rasgos melódicos de descortesía involuntaria en las peticiones realizadas con intención cortés por parte de inmigrantes sinohablantes residentes en la Comunidad de Madrid y percibidas como descorteses por parte de hablantes de español L1 igualmente residentes en la Comunidad de Madrid. Las preguntas de investigación a las que se pretende dar respuesta con este estudio son, por tanto:

- ¿Existen peticiones realizadas en español L2 con intención cortés por parte de sinohablantes que son percibidas como descorteses por hablantes de español L1?

- En caso afirmativo, ¿cuáles son los rasgos melódicos de las peticiones realizadas con intención cortés por inmigrantes sinohablantes residentes en la Comunidad de Madrid que son percibidas como descorteses por los hablantes de español L1?

\subsection{Metodología y fases de investigación}

Para responder a estas preguntas se estableció un corpus de 400 peticiones realizadas con intención cortés por parte de 20 trabajadores sinohablantes residentes en la Comunidad de Madrid. Las peticiones fueron elicitadas mediante role-play y DCT (Discourse Completion Task) oral con apoyo visual, de manera que se pudieran controlar la intención del hablante y el acto de habla producido, pero no el contenido léxico-gramatical del mismo. En segundo lugar, se realizó un test perceptivo para seleccionar los stimuli que eran percibidos como descorteses por hablantes de español L1, a pesar de la intención cortés del hablante. Estos enunciados fueron posteriormente analizados mediante el método de AMH y, en un segundo análisis, teniendo en cuenta los rasgos melódicos de la (des)cortesía en español descritos por Devís (2011). Se trata, así, de un estudio de corte cualitativo, cuyo objetivo es observar cuáles son los rasgos melódicos de las producciones realizadas con intención cortés por trabajadores sinohablantes residentes en la Comunidad de Madrid.

Este estudio se llevó a cabo en las siguientes fases:

- Fase I. Establecimiento del corpus: grabación de peticiones realizadas con intención cortés por parte de sinohablantes residentes en la Comunidad de Madrid.

- Fase II. Test de percepción de (des)cortesía de peticiones del corpus por parte de hablantes de L1 español peninsular.

- Fase III. Análisis melódico de peticiones realizadas con intención cortés y percibidas como descorteses.

- Fase IV. Análisis de rasgos melódicos de (des)cortesía, según Devís (2011). 


\subsection{Participantes}

\subsubsection{Informantes}

Para las grabaciones de este estudio se contó con la participación voluntaria de 20 informantes sinohablantes residentes en la Comunidad de Madrid durante al menos dos años. Los 20 informantes $(3 \mathrm{H}, 17 \mathrm{M})$ tenían edades comprendidas entre los 22 y los 55 años $(\mathrm{M}=35,61$; $\mathrm{DT}=9,36$ ) y estaban cursando el programa de español para trabajadores sinohablantes residentes en la Comunidad de Madrid Comunícate A2/B1. Todos los informantes habían residido al menos dos años $(M=5,95 ; \mathrm{DT}=4,98)$ en la Comunidad de Madrid en el momento en el que participaron en la grabación de los enunciados. Sin embargo, los informantes, por lo general, tenían un contacto limitado con el español, dado que en el ámbito familiar solían interactuar en su L1. Asimismo, los alumnos no habían recibido clases de español previamente, de manera que el conocimiento que habían adquirido de la lengua se debía a la limitada interacción con los hablantes de L1 durante sus actividades en el ámbito público.

\subsubsection{Jueces}

En el test de percepción participaron $92(33 \mathrm{H}, 59 \mathrm{M})$ jueces inexpertos hablantes de español L1, residentes en la Comunidad de Madrid, con edades comprendidas entre los 23 y los 59 años $(M=37 ; D T=8,71)$. El tiempo de residencia era superior a 2 años $(M=18,15 ; D T=16)$. Ninguno de ellos hablaba chino mandarín.

\subsection{Corpus}

Para establecer el corpus de peticiones se crearon tres situaciones de role-play y un DCT oral con apoyo visual con 21 situaciones. El DCT con apoyo visual se elaboró en la línea del Multimedia Elicitation Task (Schauer, 2007), con la diferencia de que la investigadora, en esta ocasión, era responsable de contextualizar y leer las situaciones mientras el informante leía el texto y observaba las imágenes. Así, el informante, además, contaba con el texto de apoyo, para confirmar la información que recibía de la investigadora. Las situaciones de role-play se elaboraron basándose en el trabajo desarrollado por Devís y Bartolí (2014). No obstante, los informantes de este estudio se encontraban en un curso de español de nivel A2/B1, por lo que se adaptaron las situaciones al nivel de dominio de la lengua de los informantes.

Las situaciones del DCT fueron creadas basándose en el nivel de dominio de español de los sinohablantes, así como en las situaciones en las que estos trabajadores sinohablantes deben comunicarse en el ámbito público. Como hemos visto, las imágenes pueden servir para enriquecer el DCT y ayudar a contextualizar la situación (Martínez-Flor y Usó-Juan, 2011; Bardovi-Harlig y Shin, 2014), especialmente cuando nos encontramos con informantes con un nivel no demasiado avanzado de español. Presentar únicamente el texto podría dar lugar a malentendidos por parte de los informantes y requeriría de más información por parte del investigador. Cabe subrayar que, en todas las situaciones, se solicitó a los informantes que se expresaran con el mayor grado de cortesía posible. De esta manera, se ha controlado la variable intención de cortesía del hablante. No obstante, no se ofreció ninguna sugerencia sobre cómo realizar la petición ni se indicó cómo dirigirse al interlocutor, de forma que la producción fuera lo más cercana a la comunicación real posible.

Una de las prioridades a la hora de construir el DCT para la recogida del corpus de peticiones semiespontáneas fue poder elicitar peticiones características de situaciones cotidianas en las que los informantes pudieran encontrarse a diario en el ámbito público. Las contextualizaciones incluían, asimismo, situaciones en las que los informantes pudieran encontrarse en el ámbito personal y privado. A la hora de grabar a los participantes, se solicitaba que el informante interactuara con la investigadora, como si de su interlocutor se tratara, de manera que la interacción fuera lo más natural y espontánea posible. 
Dado que el objetivo del presente estudio no es hacer una comparación entre la influencia de las variables sociales en español y en chino, las situaciones se plantearon con dos requisitos. Por un lado, se trataba de situaciones en las que los participantes podían encontrarse con frecuencia, correspondientes, sobre todo, al ámbito público. Por otro, en todas las situaciones se requería en español un alto grado de cortesía, algo que se explicaba detalladamente a los informantes.

A continuación, se detallan algunas de las situaciones que se plantearon a los informantes:

1. Pedir a los clientes de un restaurante que esperen un minuto antes de que se les pueda asignar una mesa.

2. Pedirle a una persona que cambie su asiento en el avión para sentarse cerca de un ser querido.

3. Pedirle a un compañero que limpie la casa ante la inminente visita de unos familiares.

4. Pedirle a alguien en la calle que le indique el camino a un hospital cercano.

5. Pedirle a un compañero de piso que le preste 100 euros para comprar un ordenador nuevo.

6. Pedir en una cafetería que se cambie el café.

7. Pedir información sobre los autobuses que van a la ciudad en el aeropuerto.

8. Pedirle a alguien que está llamando que no vuelva a llamar.

9. Pedirle una bolsa a la cajera del supermercado.

10. Pedirle a un taxista que permita el pago con tarjeta.

El DCT oral se presentó en un ordenador portátil, pero la investigadora interactuó en todo momento con cada participante. El proceso de grabación se llevó a cabo en aulas de la Universidad Nebrija. La grabación fue realizada digitalmente con una grabadora Olympus WS-852.

\subsection{Test de percepción}

Se elaboró un test de percepción de (des)cortesía con 98 enunciados y un enunciado de prueba. Los 98 stimuli fueron divididos en 3 sets: dos de 33 items y uno de 32 items. Cada set contenía, además, un ítem como audio de prueba. Así, cada test de percepción constaba de 33 o 32 stimuli, de manera que no consumiera demasiado tiempo ni esfuerzo de los participantes. Cada juez evaluaba un único set de stimuli. De esta manera, se garantizó que los participantes terminaran la prueba y que sus respuestas fueran fiables y no fruto del azar o del cansancio. Para responder al test de percepción, los jueces necesitaban únicamente 10 minutos.

El test de percepción fue distribuido online a través de la plataforma SurveyGizmo. Los jueces tenían que evaluar el grado de cortesía del enunciado en una escala de Likert de 6 puntos, siendo 0 la nota más baja y 5 la más alta. En esta ocasión se optó por una escala de 6 puntos, de manera que no hubiera un punto neutral en la evaluación y los jueces tuvieran que decantarse por una opción (cortés o descortés) (Chyung et al., 2017).

A través de las instrucciones se solicitaba a los jueces que imaginaran que los enunciados habían sido producidos dirigiéndose a ellos. La contextualización de cada situación era, por lo tanto, la misma que habían encontrado los informantes sinohablantes, pero desde la perspectiva del receptor. El test solicitaba a los informantes que se imaginaran en la situación planteada y que pensaran que la persona se dirigía a ellos. Después, los informantes podían evaluar el grado de (des)cortesía de los hablantes a la hora de enunciar la petición. Los audios podían escucharse tantas veces como los informantes estimaran oportuno. Tampoco existía una limitación en cuanto 
al tiempo. Cuando el enunciado podía ser malinterpretado por falta de claridad en la formulación del enunciado, la contextualización escrita incluía parte del texto producido por el informante sinohablante.

Los jueces únicamente recibían la instrucción de evaluar el grado de cortesía imaginándose en la situación indicada, de manera que se trataba de un juicio global, sin focalizar la atención en un rasgo concreto de la producción. Dado que el objetivo del estudio era observar un posible fenómeno de malentendido lingüístico, la contextualización de las situaciones comunicativas era esencial. A continuación, se presentan algunas de las contextualizaciones de los stimuli con las que contaban los jueces:

- A tu compañero de piso le han robado el dinero y te pide prestados 100 dólares.

- Tu compañera de piso te pide que limpies el piso porque está muy sucio.

- Eres profesor/a y una alumna te pide que enciendas el aire acondicionado en clase.

- Trabajas en un supermercado y un cliente te pide que le digas dónde está un producto.

- Trabajas en una cafetería. Una clienta te pide que le cambies el café por uno con leche de soja.

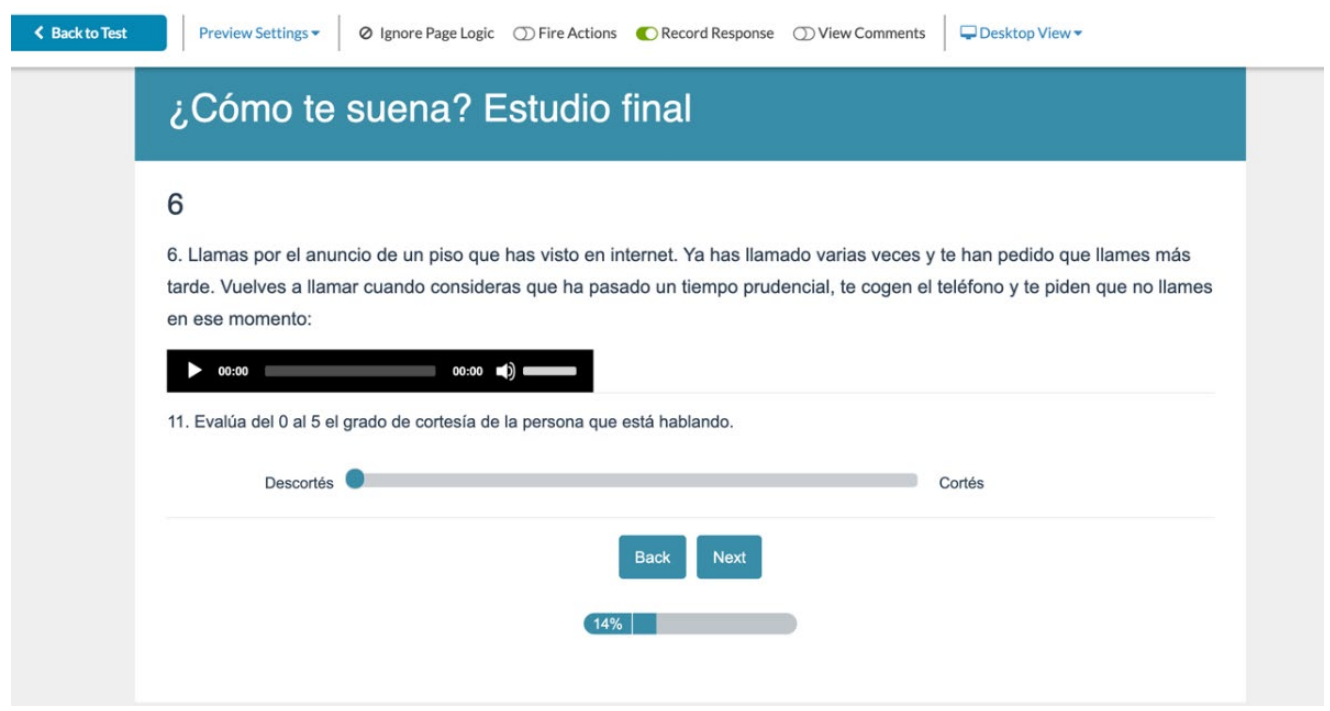

Figura 5. Imagen del test de percepción de cortesía en línea.

92 hablantes de español L1 residentes en la Comunidad de Madrid por al menos 2 años participaron en este estudio. 33 jueces respondieron al set 1,32 jueces respondieron al set 2 y 27 jueces respondieron al set 3 de enunciados contextualizados. Cada informante escuchó los audios en un orden aleatorio diferente.

\section{Resultados}

De los 98 stimuli presentados en los 3 tests de percepción, solo 15 fueron percibidos como completamente descorteses, es decir, obtuvieron una nota media de descortesía inferior a 2 en una escala del 0 al 6 , siendo 0 "muy descortés" y 6 "muy cortés". Para comprobar el grado de acuerdo entre los jueces y detectar posibles jueces outliers se utilizó el coeficiente de correlación intraclase, que determinó la existencia de un alto grado de acuerdo (ICC $=>0.9$ ) entre los jueces 
en cada set (el coeficiente se situó en todos los casos en el rango de "excelente" $-\mathrm{ICC}=0.942$ en el set 1 ; ICC $=0.923$ en el set 2 ; ICC $=0.902$ en el set 3 ).

Los enunciados percibidos, así, como descorteses fueron analizados siguiendo el protocolo para el Análisis Melódico del Habla (Cantero y Font-Rotchés, 2009, 2020). Para ello, primero, se tomaron los valores relevantes de F0 (principalmente vocales) del enunciado y se calculó el porcentaje de variación de cada valor absoluto respecto al valor anterior. El valor de cada vocal en Hercios corresponde a la media de todos los valores absolutos a lo largo de la vocal. Con los valores y los porcentajes se dibujaron los gráficos que representan las melodías. De los 15 enunciados, uno fue descartado del análisis por presentar deficiencias en la calidad de la grabación que afectaban a su análisis en Praat (Boersma, 2001). Por lo tanto, el corpus definitivo con los enunciados percibidos como claramente descorteses para su posterior análisis quedó constituido por 14 enunciados. A continuación, presentamos los 14 enunciados analizados para el presente estudio:

1. Ayúdame 100 euros para comprar un ordenador.

2. Espera

3. ¿Puede cien dólar para mí?

4. Un minuto.

5. No llama más.

6. Por favor, no me llames ahora.

7. Puede hacer tus cosas bien, está muy sucio.

8. Llama a mi madre.

9. Perdona, no me llama más.

10.Puede callarte.

11.¿Puede cambiarme?

12.¿Me puede poner de soja?

13.Enciende el aire acondicionado.

14.Quiero que tú cambie.

Como podemos observar, los enunciados no son equiparables desde el punto de vista léxicogramatical. Esto se debe al hecho de que el contenido léxico-gramatical del enunciado no fue controlado para el estudio, de manera que las producciones fueran similares a las realizadas por los informantes en situaciones de comunicación real. Si bien el contenido léxico-gramatical puede influir considerablemente en el juicio de cortesía del enunciado, nuestro objetivo es observar los rasgos melódicos que, independientemente del contenido léxico-gramatical, pueden encontrarse en todos los enunciados percibidos como descorteses.

Como hemos visto, Devís (2011: 63) hipotetizó que los siguientes rasgos melódicos podían caracterizar los enunciados descorteses en español:

- Inflexiones finales descendentes iguales o superiores al 30\% (en ocasiones con varios segmentos y a menudo con pico elevado).

- Esquema con un único pico.

- Prominencias en átonas muy marcadas (superiores al 50\%).

- Esquema en zigzag con contornos interiores muy ascendentes (normalmente entre el $20 \%$ y el $40 \%$, aunque hay casos de hasta el $60 \%$ y el $90 \%$ ).

- Énfasis de palabra con ascensos de hasta el 90\%.

La misma autora comprobó (Devís, 2011: 75) que los siguientes rasgos constituían un código semiestable de intensificación de la descortesía:

- Intensificación de más de una vocal tónica (con ascensos superiores al 50\%) formando un contorno en zigzag.

- Intensificación de más de una vocal átona (con ascensos superiores al 50\%) junto con un final descendente (superior al 30\%). 
Teniendo en cuenta los resultados de este estudio (Devís, 2011), se analizaron los enunciados percibidos como descorteses y se encontraron los siguientes rasgos melódicos que pueden ser causa de dicha percepción, a pesar de la intención cortés de los hablantes. A continuación, se presentan ejemplos de los rasgos melódicos de descortesía encontrados en los enunciados producidos por los informantes sinohablantes con intención cortés y percibidos como claramente descorteses por los hablantes de español L1.

\subsection{Contorno en zigzag}

La intensificación de más de una vocal tónica que resulta en un contorno en zigzag característico de la intensificación descortés en español es el rasgo melódico más presente en los enunciados del corpus. Los Gráficos 1, 2 y 3 son buenos ejemplos de contornos en zigzag. En todos los casos, los énfasis tonales se encuentran en las vocales tónicas, rasgo característico de la descortesía en español (Devís, 2011).

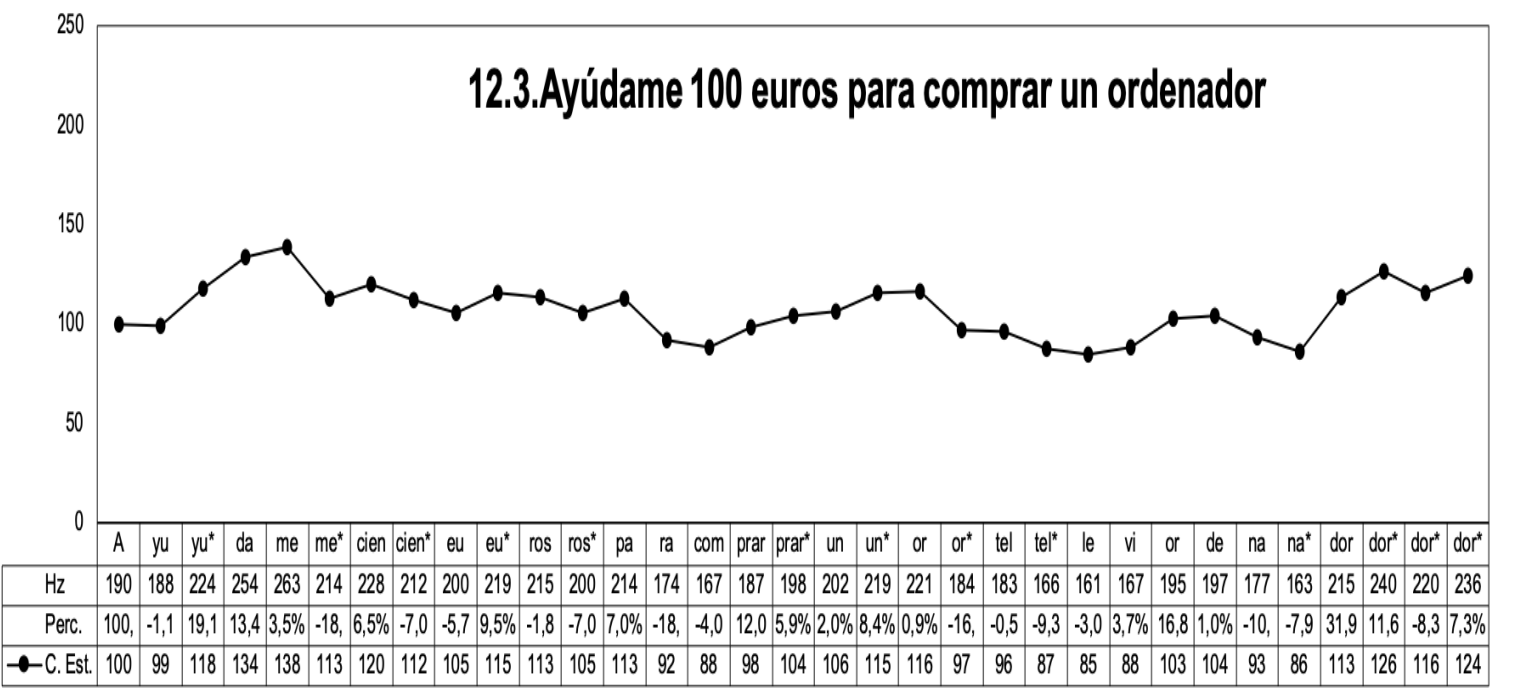

Gráfico 1. Contorno melódico en zigzag: Ayúdame 100 euros para comprar un ordenador.

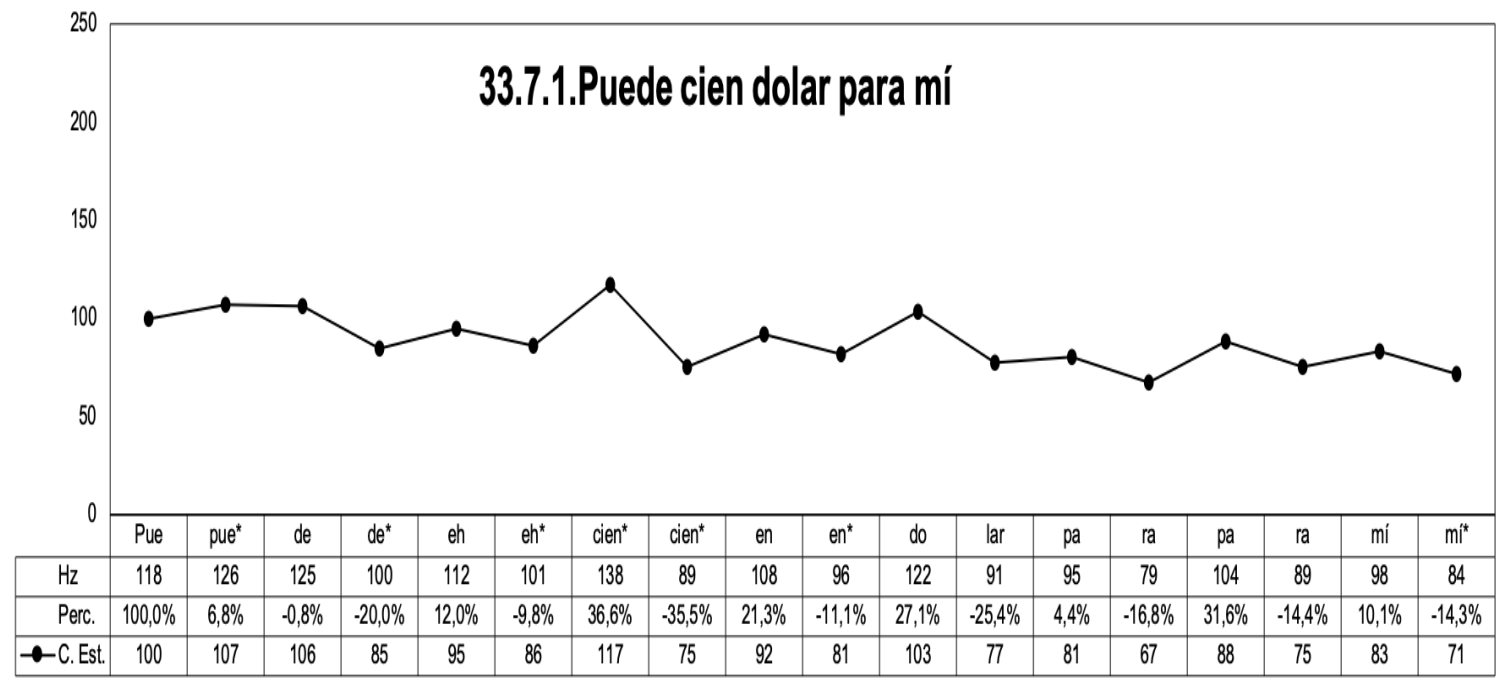

Gráfico 2. Contorno melódico en zigzag: Puede cien dolar para mí. 


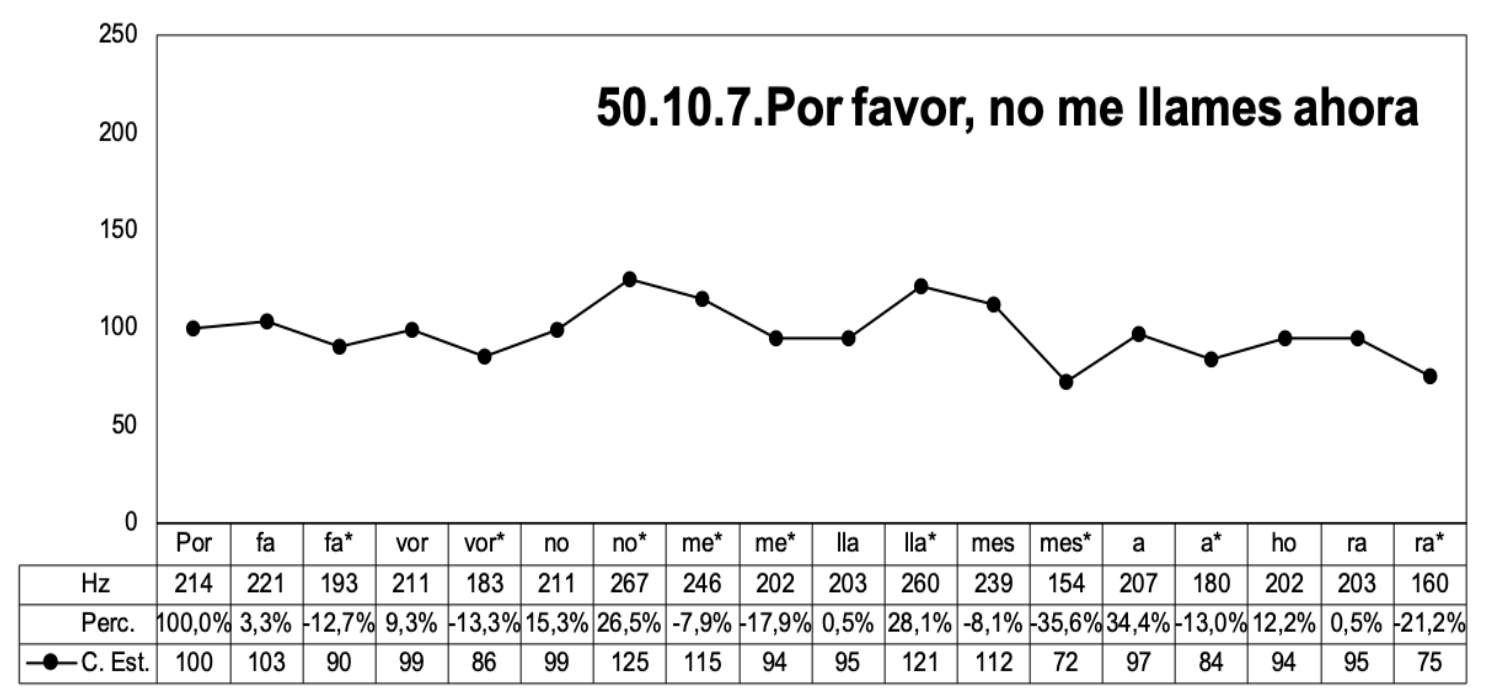

Gráfico 3. Contorno melódico en zigzag: Por favor, no me llames ahora.

\subsection{Esquema con un único pico}

En el Gráfico 4 podemos observar un ejemplo de esquema con un único pico. El pico tonal, además, se encuentra en la palabra "no", y seguido de un claro descenso tonal. Esto puede ser un claro ejemplo de foco estrecho o énfasis de palabra (Cantero et al, 2005).

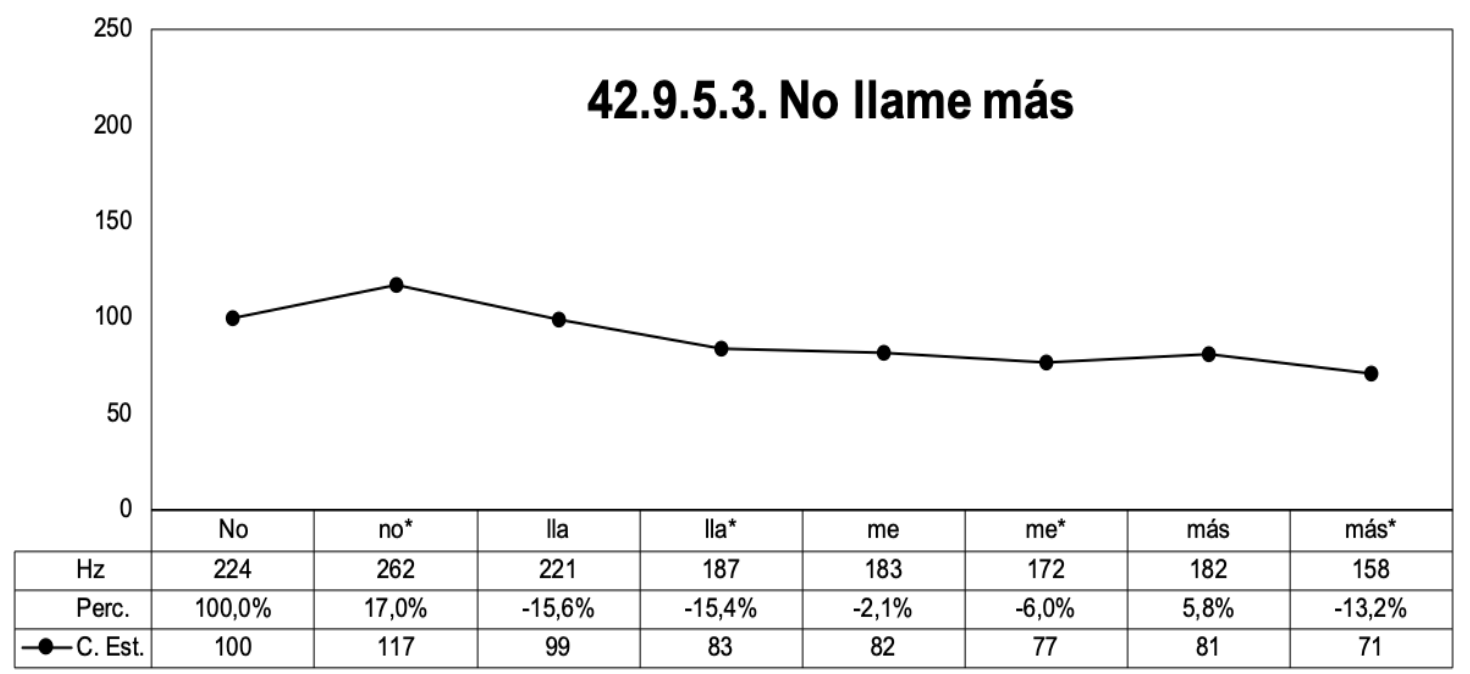

Gráfico 4. Esquema con un único pico: No llame más.

\subsection{Inflexión final descendente}

El Gráfico 5 muestra un ejemplo de una inflexión final descendente. Además, el descenso tonal de la inflexión es pronunciado (-22,6\%). Al mismo tiempo, podemos observar en el enunciado un énfasis tonal en las sílabas tónicas. 


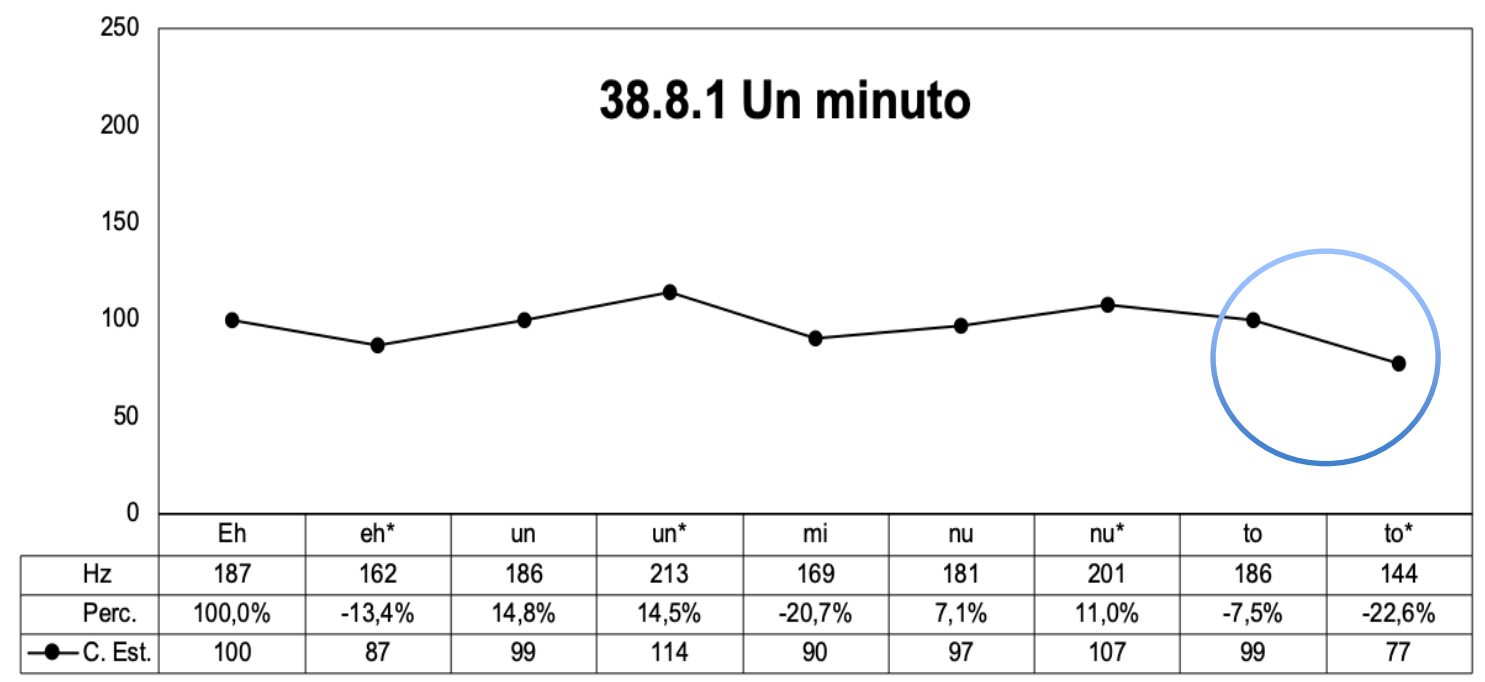

Gráfico 5. Inflexión final descendente: Un minuto.

\subsection{Prominencia en átona muy marcada}

El Gráfico 6 muestra un enunciado con una inflexión tonal y un énfasis muy pronunciado en la átona "de". En total, se trata de un $41,9 \%$ de énfasis tonal.

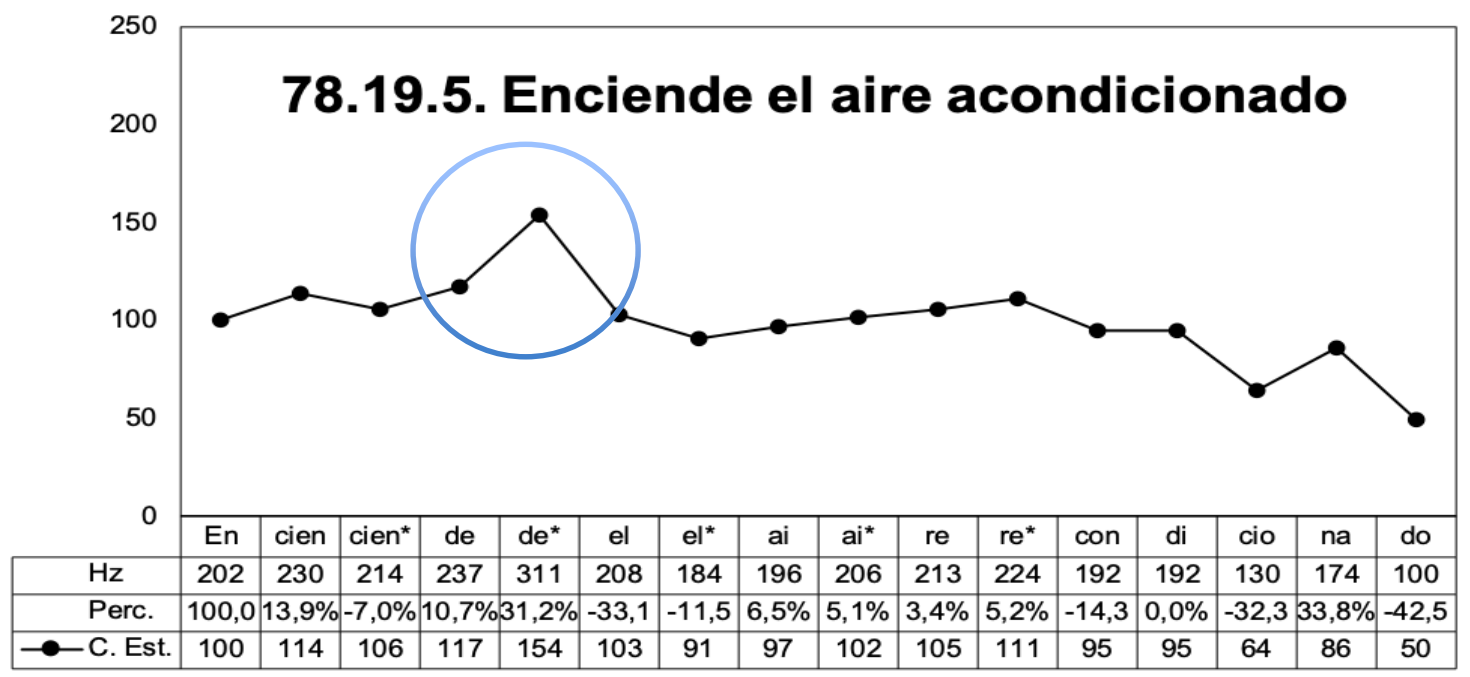

Gráfico 6. Prominencia marcada en átona: Enciende el aire acondicionado.

\section{5. Énfasis de palabra}

En el Gráfico 7 podemos encontrar un ejemplo de énfasis de palabra o fenómeno de foco estrecho en las palabras "no" y "llames". El ascenso tonal más marcado en este enunciado se encuentra, como hemos visto en el Gráfico 4 anteriormente, en la palabra "no". Asimismo, el gráfico muestra cómo el hablante ha decidido hacer énfasis en la sílaba "lla" de "llames". Además, en el Gráfico 8 podemos observar una inflexión tonal y un énfasis tonal en la palabra "tú". 


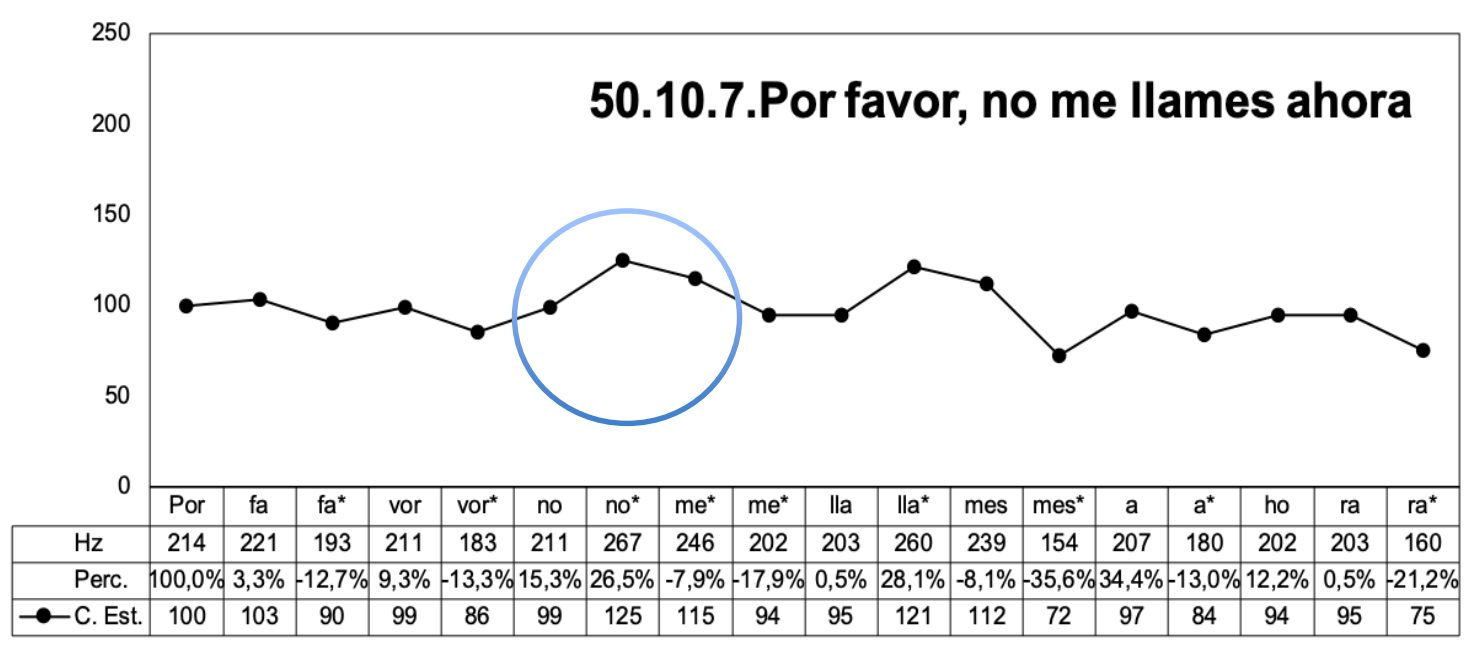

Gráfico 7. Énfasis de palabra: Por favor, no me llames ahora.

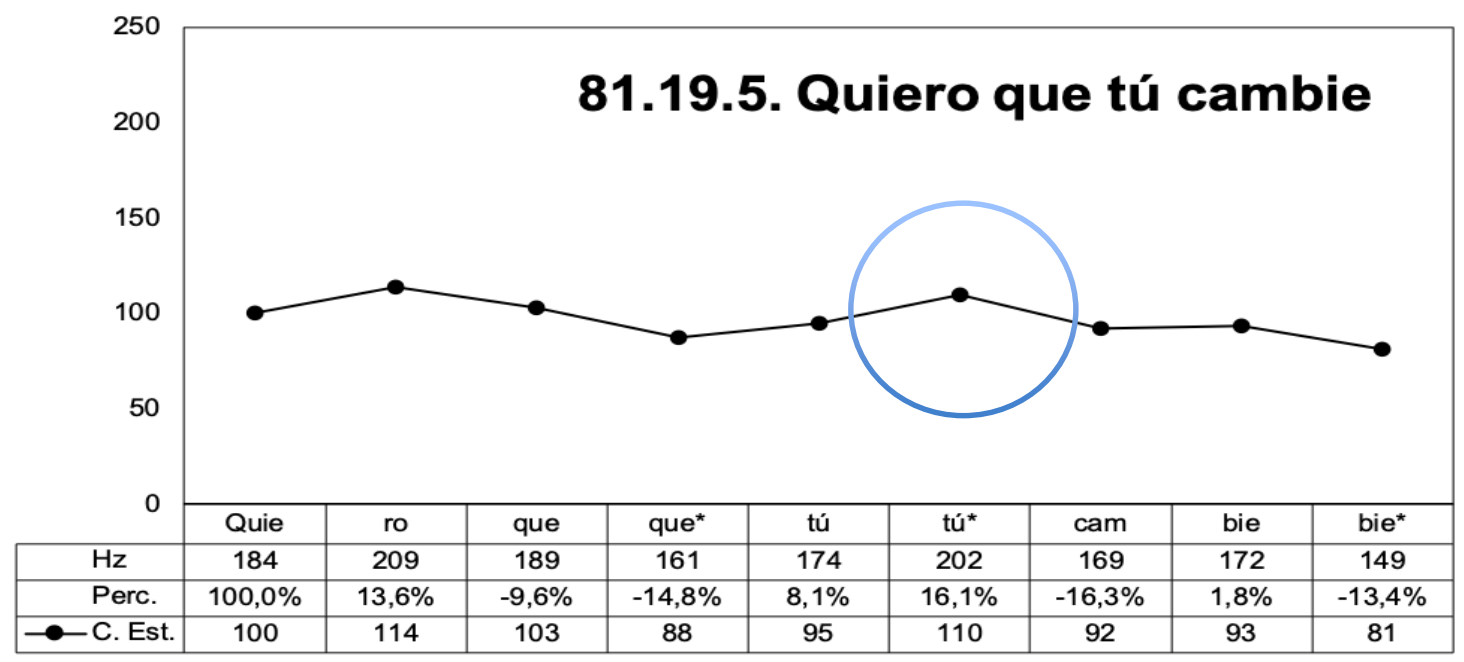

Gráfico 8. Énfasis de palabra: Quiero que tú cambie.

Como podemos observar, en la mayor parte de los casos podemos encontrar varios rasgos melódicos de descortesía que actúan en interacción. A continuación, se incluye una tabla con los rasgos melódicos de descortesía presentes en cada uno de los enunciados percibidos como descorteses.

\begin{tabular}{|l|c|c|c|c|c|c|c|c|c|c|c|c|c|c|}
\hline Enunciado & $\mathbf{1}$ & $\mathbf{2}$ & $\mathbf{3}$ & $\mathbf{4}$ & $\mathbf{5}$ & $\mathbf{6}$ & $\mathbf{7}$ & $\mathbf{8}$ & $\mathbf{9}$ & $\mathbf{1 0}$ & $\mathbf{1 1}$ & $\mathbf{1 2}$ & $\mathbf{1 3}$ & $\mathbf{1 4}$ \\
\hline Inflexión final descendente & & $\mathrm{x}$ & $\mathrm{x}$ & $\mathrm{x}$ & $\mathrm{x}$ & $\mathrm{x}$ & $\mathrm{x}$ & $\mathrm{x}$ & $\mathrm{x}$ & $\mathrm{x}$ & $\mathrm{x}$ & $\mathrm{x}$ & & $\mathrm{x}$ \\
\hline Esquema con un único pico & & & & & $\mathrm{x}$ & & & & & & & & & \\
\hline $\begin{array}{l}\text { Prominencia en átona muy } \\
\text { marcada }\end{array}$ & & & & & & & & & $\mathrm{x}$ & & & & $\mathrm{x}$ & \\
\hline Esquema en zigzag & $\mathrm{x}$ & $\mathrm{x}$ & & $\mathrm{x}$ & & $\mathrm{x}$ & $\mathrm{x}$ & & $\mathrm{x}$ & & & & $\mathrm{x}$ & $\mathrm{x}$ \\
\hline Énfasis de palabra & & & & & $\mathrm{x}$ & $\mathrm{x}$ & $\mathrm{x}$ & & $\mathrm{x}$ & & $\mathrm{x}$ & $\mathrm{x}$ & $\mathrm{x}$ & $\mathrm{x}$ \\
\hline Prominencia en vocales tónicas & $\mathrm{x}$ & $\mathrm{x}$ & $\mathrm{x}$ & $\mathrm{x}$ & $\mathrm{x}$ & $\mathrm{x}$ & $\mathrm{x}$ & $\mathrm{x}$ & & $\mathrm{x}$ & $\mathrm{x}$ & & $\mathrm{x}$ & \\
\hline
\end{tabular}

Tabla 1. Rasgos melódicos de descortesía en enunciados percibidos como descorteses. 
En la tabla se puede apreciar que el rasgo melódico con una mayor presencia en el corpus de peticiones involuntariamente descorteses es la inflexión final descendente, presente en el 85,71\% de los enunciados. El segundo rasgo melódico de descortesía más presente en los enunciados es la prominencia en vocales tónicas, que se puede encontrar en el 78,5\% de los enunciados. El énfasis de palabra o fenómeno de foco, al igual que el esquema en zigzag, se pudo encontrar en 8 enunciados, es decir, en el $57,1 \%$ de las peticiones descorteses. Por otro lado, es interesante observar que en la mayor parte de los enunciados se encuentran varios rasgos melódicos de descortesía diferentes, de manera que estos actúan en interacción.

\section{Discusión de los resultados}

El objetivo de este estudio era observar si, en el caso de las peticiones realizadas con intención cortés por parte de inmigrantes sinohablantes residentes en la Comunidad de Madrid, se podría observar el fenómeno de la descortesía involuntaria y, de ser así, si se podrían encontrar rasgos melódicos de descortesía característicos de la descortesía en español (Devís, 2011). Para ello, se elicitó un corpus de peticiones y se seleccionaron los enunciados percibidos como muy descorteses a través de una prueba perceptiva con jueces hablantes de español L1.

Tras analizar los resultados, se ha podido observar que, a pesar de la intención extremadamente cortés de los informantes, algunos enunciados, efectivamente, fueron percibidos como claramente descorteses. Se trata, así, de un caso evidente de descortesía involuntaria (Bousfield y Culpeper, 2008; Kaul, 2008) o de cortesía desacertada (Ridao, 2009) que se puede dar en situaciones de comunicación intercultural y que, por lo tanto, merece ser estudiado en profundidad. Como podemos observar en los ejemplos analizados, los enunciados que contienen elementos tradicionalmente considerados corteses desde el punto de vista léxico-gramatical, como es el caso de las oraciones interrogativas, o de aquellas que contienen expresiones de cortesía como "por favor". Sin embargo, a pesar de estos elementos de cortesía, los enunciados han sido percibidos como totalmente descorteses, lo que sugiere que existen rasgos en otros niveles de la lengua que le confieren el marcado carácter descortés.

Igual que hiciera Devís (2017) sobre la percepción de cortesía involuntaria en el discurso neutro de brasileños en español, se hipotetizó en este estudio que los rasgos melódicos podrían ser responsables de dicha percepción de descortesía involuntaria, de manera que se realizó un análisis melódico con AMH de los enunciados percibidos como claramente descorteses por el panel de jueces. Tras analizar desde el punto de vista melódico estos 14 enunciados, se observó que todos ellos contenían rasgos melódicos característicos de la descortesía en español peninsular, según la descripción de la entonación de descortesía realizada en estudios anteriores (Devís, 2011).

Los rasgos que han aparecido con mayor frecuencia en el corpus son las inflexiones finales descendentes, las prominencias en tónicas, el énfasis de palabra y los esquemas en zigzag con contornos interiores ascendentes. Este esquema en zigzag característico de muchos de los enunciados percibidos como descorteses se produce como consecuencia de la observada inestabilidad tonal inter- e intrasilábica (Liu, 2005) característica de la interlengua fónica del español hablado por sinohablantes. Por otro lado, los casos frecuentes de énfasis de palabra y prominencia tonal en sílaba tónica pueden tener relación con el denominado efecto staccato (Cortés, 2004) presente en el español hablado por chinos, debido a una tendencia de los sinohablantes a pronunciar sílaba por sílaba, es decir, una dificultad a la hora de entonar en español por grupos fónicos.

Esta presencia de los rasgos melódicos de descortesía en el español hablado por los sinohablantes percibidos como descorteses a pesar de haber sido producidos con una clara intención cortés nos lleva a pensar que dichos rasgos podrían ser responsables de la mencionada percepción de descortesía involuntaria. No obstante, más estudios son necesarios para comprobar dicha hipótesis, ya que, en este, los rasgos melódicos no están aislados y no son los únicos que podrían 
ser responsables de la interpretación descortés por parte de los jueces hispanohablantes. En este caso, los rasgos melódicos no solo se combinan con otros rasgos prosódicos como la intensidad, la duración o rasgos relativos a la cualidad de voz, que podrían ser igualmente responsables del fenómeno de cortesía desacertada, sino que los mensajes, al haber sido producidos de manera libre, se caracterizaban por contener rasgos léxico-gramaticales muy dispares, por lo que los rasgos responsables de la percepción de descortesía involuntaria podrían ser rasgos lingüísticos de tipo léxico-gramatical, característicos del bajo nivel de dominio de la lengua de los participantes.

\section{Conclusiones}

Aunque siga existiendo la creencia generalizada (García-Andreva, 2014) de que la inmersión lingüística es capaz, por sí sola, de facilitar el proceso de adquisición de la pronunciación, el componente fónico, especialmente la entonación, es uno de los más difíciles de adquirir en una lengua extranjera (Cortés, 2000). Asimismo, la prosodia es un factor con un papel muy relevante en la comunicación intercultural que puede dar lugar a interpretaciones erróneas de la intención comunicativa del hablante y, por lo tanto, causar malentendidos en situaciones en las que participan inmigrantes o solicitantes de asilo (Sperti, 2017), situaciones marcadas por una clara asimetría entre los participantes en la interacción (Guido, 2008).

Los resultados de este estudio parecen indicar que los enunciados realizados con intención cortés por parte de algunos participantes sinohablantes y percibidos como descorteses por parte de los informantes hispanohablantes, es decir, aquellos donde se ha producido el fenómeno de la descortesía involuntaria, se caracterizan por contener varios de los rasgos melódicos de descortesía descritos por Devís (2011). Si bien es importante subrayar que este no es el caso en todas las producciones de todos los hablantes sinohablantes de español L2, parece relevante el hecho de que al menos algunos informantes sean percibidos como descorteses a pesar de su intención cortés. Sería conveniente analizar en el futuro en profundidad, en primer lugar, si son estos rasgos melódicos los responsables de dicha percepción de descortesía y, en segundo lugar, cuáles pueden ser las razones por las que los hablantes no son conscientes de este fenómeno al comunicarse en español. Asimismo, sería interesante analizar los enunciados percibidos como corteses para observar si estos sí contienen los rasgos melódicos de cortesía expuestos por Devís (2011).

Al igual que Flege y Wayland (2019), consideramos que los migrantes hablantes de L2 que constituyen nuestro corpus de informantes pueden no haber recibido input de calidad, es decir, con hablantes de español L1, algo que podría haber mejorado su capacidad de producción de la entonación de (des)cortesía en español. Otra causa podría encontrarse en la falta de instrucción explícita de la lengua, dado que ninguno de los participantes sinohablantes en el estudio había recibido instrucción en español como lengua extranjera antes de acudir al curso Comunícate organizado por la Universidad Nebrija. Así, probablemente, los resultados de este estudio habrían sido diferentes si se hubiera contado con hablantes de niveles más avanzados o que hubieran contado con una mayor exposición a la L2.

Asimismo, como ya hemos subrayado, los resultados de este estudio son insuficientes para afirmar que los rasgos melódicos de descortesía presentes en los enunciados producidos con intención cortés son responsables de la percepción de descortesía. Otros rasgos melódicos o, incluso, otras características a nivel léxico-gramaticales como la ausencia de determinadas expresiones de cortesía ("por favor", "disculpe"), podrían ser responsables de la percepción de descortesía. No obstante, conviene subrayar que algunos de los enunciados percibidos como completamente descorteses incluían, de hecho, este tipo de estructuras, lo cual nos lleva a pensar en el peso de otros aspectos -en este caso, los rasgos melódicos- en dicha percepción de descortesía. Por lo tanto, es necesario complementar los resultados de este estudio con estudios posteriores en los que se aíslen y manipulen los rasgos melódicos. Solo entonces, después de observar si modificando únicamente los rasgos melódicos los sinohablantes que han sido percibidos como 
descorteses por los jueces hispanohablantes a pesar de su intención son percibidos como corteses, se podrá concluir que los rasgos melódicos son responsables de semejante malentendido lingüístico.

Por otro lado, cabe subrayar que, para este trabajo, únicamente se han tenido en cuenta los aspectos melódicos de la lengua. Sería relevante, en futuras investigaciones, tener en cuenta otros niveles prosódicos como el ritmo o juego de duraciones (Cantero, 2020) y la dinámica o juego de intensidades (Cantero, 2020), mediante análisis más completos que pudieran revelar si otros rasgos prosódicos podrían tener relación con la percepción de la descortesía involuntaria en las peticiones realizadas con intención cortés por parte de sinohablantes en español L2. Por ello, se considera relevante continuar con investigaciones mediante el recientemente creado análisis prosódico del habla (Cantero, 2019), modelo de análisis que servirá para realizar observaciones de gran alcance en el campo del análisis de la (des)cortesía (Cantero, 2020), tanto en L1 como en L2. El análisis prosódico, tanto en L1 como L2, podrá ayudarnos a comparar en profundidad qué rasgos prosódicos pueden ser más relevantes en la percepción de la (des)cortesía en diferentes lenguas.

Como indica Cantero (2002), la entonación expresiva es aquella producida de manera consciente "por el hablante para transmitir un contenido afectivo o motivado directamente por la emoción" (2002: 192). Aunque el límite entre ambos es, como subraya el autor, muy delgado, es importante tener en cuenta que es de vital importancia para hablantes de lenguas extranjeras dominar estas estrategias de la entonación expresiva o actitudinal para poder expresar y comprender la intención adecuada, especialmente en situaciones en las que malentendidos lingüísticos pueden tener graves consecuencias.

A pesar de que cada vez es más evidente la imposibilidad de observar cualquier fenómeno a nivel pragmático sin tener en cuenta la prosodia (Hidalgo y Cabedo, 2014) y del creciente reconocimiento que ha comenzado a recibir la fonética dentro del estudio de la pragmática y de la lingüística aplicada a la enseñanza de lenguas, son escasos los estudios empíricos que se centran en los aspectos prosódicos concretos que pueden dificultar la comunicación eficaz en L2. No obstante, es importante que los hablantes de lenguas extranjeras sean capaces de comunicarse de acuerdo a su intención comunicativa y con los matices deseados y, para ello, es indispensable la concienciación sobre la relevancia de la prosodia. Este, sin lugar a dudas, debería ser el principal objetivo de los profesores de lenguas extranjeras que durante tanto tiempo han relegado la pronunciación a un segundo plano, debido, probablemente, a la dificultad de su enseñanza, o a las implicaciones ideológicas que se pudieran desprender de la cada vez más obsoleta obsesión por la reducción del acento extranjero.

\section{Referencias bibliográficas}

Álvarez, A., y Blondet, M.A. (2003). Cortesía y prosodia: Un estudio de la frase cortés en el español de Mérida (Venezuela). En E. Herrera Z. y P. Martín Butragueño (Eds.). La Tonía. Dimensiones Fonéticas y Fonológicas, (pp. 319-330). El Colegio de México.

Astruc, L., y Vanrell, M. M. (2016). Intonational phonology and politeness in L1 and L2 spanish. Probus, 28 (1), 91-118. https://doi.org/10.1515/probus-2016-0005

Bardovi-Harlig, K., y S. Y. Shin (2014). Expanding traditional testing measures with tasks from L2 pragmatics research. Iranian Journal of Language Testing, 4 (1), 26-49.

Bednarz, F. (2017). Professional and social integration of migrants and language learning: Convergences and challenges at the European level. En J.-C. Beacco, H.-J. Krumm, D. Little y $\mathrm{Ph}$. Thalgott (Eds.). The Linguistic Integration of Adult Migrants/L'intégration Linguistique Des Migrants Adultes: Some Lessons from Research/Les Enseignements De La Recherche (pp. 7581). De Gruyter Mouton. https://doi.org/10.1515/9783110477498-010 
Boersma, P. (2001). Praat, a system for doing phonetics by computer. Glot.International, 5 (9), 341-345.

Bousfield, D., y J. Culpeper (2008). Impoliteness: Eclecticism and diaspora. An introduction to the special edition. Journal of Politeness Research, 4 (2), 161-168. https://doi.org/10.1515/JPLR.2008.008

Briz, A. (2004). Cortesía verbal codificada y cortesía verbal interpretada en la conversación. En D. Bravo y A. Briz (Eds.), Pragmática sociocultural. Estudios sobre el discurso de cortesía en español. (pp. 67-92). Ariel.

Briz, A., y Albelda, M. (2013). Una propuesta teórica y metodológica para el análisis de la atenuación lingüística en español y portugués. La base de un proyecto en común (ES.POR.ATENUACIÓN)», Onomázein, 28, 288-319. https://doi.org/10.7764/onomazein.28.21

Briz, A., e Hidalgo, A. (2008). Marcadores discursivos y prosodia: observaciones sobre su papel modalizador atenuante. En A. Briz et al. (eds.). Cortesía y conversación: de lo escrito a lo oral (pp. 390-409). Universidad de Valencia, Programa EDICE.

Cantero, F. J. (2002). Teoría y análisis de la entonación. Edicions de la Universitat de Barcelona.

Cantero, F. J., Alfonso, R., Bartolí, M., Corrales, A., y Vidal, M. (2005). Rasgos melódicos de énfasis en español. Phonica, 1, 1-40.

Cantero, F. J. (2014). Códigos de la entonación y entonación emocional. En A. Díaz et al. (Eds.). Comunicación, Cognición, Cibernético. Actas del 31er Congreso Internacional de la Asociación de Lingüistica Aplicada (pp. 618-629). Universidad de La Laguna.

Cantero, F. J. (2019). Análisis prosódico del habla: más allá de la melodia. En M. R. Álvarez Silva, A. Muñoz Alvarado y L. Ruiz Miyares (Eds.). Comunicación Social: Lingüística, Medios Masivos, Arte, Etnología, Folclor y otras ciencias afines. Vol. II. (pp. 485-98). Ediciones Centro de Lingüística Aplicada.

Cantero, F. J. (2020). Expresión y contacto: dimensiones de la afectividad en prosodia. Moenia, 25, 521-537.

Cantero, F. J., y Font-Rotchés, D. (2009). Protocolo para el análisis melódico del habla. Estudios de fonética experimental, 18, 17-32.

Cantero, F.J.; Font-Rotchés, D. (2020). Melodic Analysis of Speech (MAS). Phonetics of Intonation. En J. Abasolo, I. de Pablo, y A. (Eds.) Contributions on education (pp.20-47). Universidad del País Vasco.

Chao, Y. R. (1933). Tone and intonation in Chinese, Bulletin of the Institute of History and Philology, 4 (2), 121-134.

Chyung, S. Y., Roberts, K., Swanson, I., y Hankinson, A. (2017). Evidence-based survey design: The use of a midpoint on the Likert scale. Performance Improvement, 56 (10), 15-23. https://doi.org/10.1002/pfi.21727

Cortés, M. (1997). Sobre la percepción y adquisición de la entonación española por parte de hablantes nativos de chino. Estudios de Fonética Experimental, IX: 67-134.

Cortés, M. (1999). Adquisición de la entonación española por parte de hablantes nativos de chino. [Tesis doctoral, Universidad de Barcelona].

Cortés, M. (2002). Didáctica de la entonación: Una asignatura pendiente. Didáctica. Lengua y Literatura, 14, 65-75. https://revistas.ucm.es/index.php/DIDA/article/view/DIDA0202110065A 
Cortés, M. (2004). Análisis acústico de la producción de la entonación española por parte de sinohablantes. Estudios De Fonética Experimental, XIII, 80-110.

Cortés, M. (2005). Análisis experimental del aprendizaje de la acentuación y la entonación españolas por parte de hablantes nativos de chino. Phonica, 1, 1-25.

Devís, E. (2011). La entonación de (des)cortesía en el español coloquial. Phonica, 7, 36-79.

Devís, E. (2017). Entonación de cortesía involuntaria en el español hablado por brasileños. Phonica, 13, 18-31. https://doi.org/10.1344/phonica.2017.13.18-31

Devís, E., y Cantero, F. J. (2014). The intonation of mitigating politeness in catalan. Journal of Politeness Research, 10 (1), 127-149. https://doi.org/10.1515/pr-2014-0006

Devís, E., y Bartolí, M. B. (2014). La enseñanza de la entonación (des) cortés en ELE: propuestas didácticas destinadas al nivel B1. Quaderns de Filologia-Estudis Lingüistics, 19, 153-171.

Fan, P., y Gu, W. (2016). Prosodic cues in polite and rude mandarin speech. [Presentación de comunicación]. 10th International Symposium on Chinese Spoken Language Processing (ISCSLP), Tianjin, China.

Flege, J. E., y Wayland, R. (2019). The role of input in native Spanish Late learners' production and perception of English phonetic segments. Journal of second language studies, 2 (1), 1-44. https://doi.org/10.1075/jsls.00004.fle

García-Andreva, F. (2014). Teoría y aplicación didáctica de la entonación para la enseñanza de E/LE. En N. M. Izquierdo (Ed.). La enseñanza del Español como LE/L2 en el siglo XXI (pp. 309320). ASELE.

Grünhage-Monetti, M., y Svet, A. (2017). "The fight against exclusion from the labour marketbegins... in the workplace": Work-related second language development towards inclusion and participation. En J. C. Beacco, H. J. Krumm, D. Little y Ph. Thalgott (Eds.). The Linguistic Integration of Adult Migrants/L'intégration Linguistique Des Migrants Adultes: Some Lessons from Research/Les Enseignements De La Recherche (pp. 315-320). De Gruyter Mouton. https://doi.org/10.1515/9783110477498-043

Guido, M. G. (2008). English as a lingua franca in cross-cultural immigration domains (Vol. 84). Peter Lang.

Haverkate, H. (1994). La cortesía verbal. Estudio Pragmalingüístico. Gredos.

Hidalgo, A. (2001). Modalidad oracional y entonación. Notas sobre el funcionamiento pragmático de los rasgos suprasegmentales en la conversación. Moenia,7, 271-92.

Hidalgo, A. (2006). La expresión de la cortesía en español hablado: marcas y recursos prosódicos para su reconocimiento en la conversación coloquial. En M. Villayandre Llamazares (Ed.). Actas del XXXV Simposio Internacional de la Sociedad Española de Lingüística (pp. 957-979). Universidad de León.

Hidalgo, A. (2007). Sobre algunos recursos fónicos del español y su proyección socio-pragmática: atenuación y cortesía en la conversación coloquial. Quaderns de Filologia, Estudis Lingüistics $12,129-42$.

Hidalgo, A. (2009). Modalización (des)cortés y prosodia: estado de la cuestión en el ámbito hispánico. Boletín de Filología, 44 (1), 161.

Hidalgo, A., y Cabedo, A. (2014). On the Importance of the Prosodic Component in the Expression of Linguistic Im/politeness. Journal of Politeness Research, 10 (1), 5-27. https://doi.org/10.1515/pr-2014-0002 
Kaul, S. (2008). Tipología del comportamiento verbal descortés en español. En Antonio BrizGómez et al. (Eds.). Cortesía y conversación: de lo escrito a lo oral. Tercer coloquio internacional del programa Edice (pp. 254-266). Universidad de Valencia-Programa Edice.

Li, A., Fang, Q., y Dang, J. (2011). Emotional intonation in a tone language: experimental evidence from Chinese. En Proceedings of the 17th International Congress of Phonetic Sciences (1198-1201). Hong Kong.

Liu, Y. H. (2005). La entonación del español hablado por taiwaneses. Biblioteca Phonica,2. [Tesis doctoral, Universitat de Barcelona]. http://www.edicions.ub.edu/revistes/phonicabiblioteca/esp taiw/esp taiw.pdf

Machetti, S., y Rocca, L. (2017). Integration of migrants, from language proficiency to knowledge of society: The italian case. En J. C. Beacco, H. J. Krumm, D. Little y Ph. Thalgott (Eds.). The Linguistic Integration of Adult Migrants/L'intégration Linguistique Des Migrants Adultes: Some Lessons from Research/Les Enseignements De La Recherche. De Gruyter Mouton. https://doi.org/10.1515/9783110477498-029

Martínez-Flor, A., y E. Usó-Juan (2011). Research methodologies in pragmatics: eliciting refusals to requests. Estudios de Lingüística Inglesa Aplicada, 11, 47-87.

Müller-Liu, P. (2006). Signalling affect in Mandarin Chinese-the role of non-lexical utterancefinal edge tones. ISCA Archive. Speech Prosody, 2-5.

Navarro Tomás, T. (1944). Manual de entonación española. Hispanic Institute in the United States.

Orozco, L. (2008). Peticiones corteses y factores prosódicos. En Z.E. Herrera y P. Martín Butragueño (Eds.). Fonología Instrumental. Patrones Fónicos y Variación, (pp. 335-355). El Colegio de México.

Quilis, A. (1988). Estudio comparativo entre la entonación portuguesa (de Brasil) y la española. Revista De Filología Española, $68 \quad(1 / 2), \quad 33-65$. https://doi.org/10.3989/rfe.1988.v68.i1/2.412

Quilis, A. (1993). Tratado de fonología y fonética españolas. Madrid: Gredos.

Ridao, S. (2009). Las estrategias de (des)cortesía en las mediaciones laborales, Editum.

Roldán, Y. (2000). Correlatos acústicos de actos de habla atenuados del español de Chile. Onomázein, 5, 107-118.

Schauer, G. A. (2007). Finding the right words in the study abroad context: The development of German learners' use of external modifiers in English. Intercultural Pragmatics, 4 (2), 193-220. https://doi.org/10.1515/IP.2007.011

Shen, X-N. S. (1990). The Prosody of Mandarin Chinese. University of California Press.

Sperti, S. (2017). Introduction: a phonopragmatic approach to the analysis of ELF cross-cultural communication. Centro di Ricerca sulle Lingue Franche nella Comunicazione Interculturale e Multimediale. Working Papers, (3), 5-7. https://doi.org/10.1285/i24991449n3p5

Waltereit, R. (2005). La polifonía prosódica: Copiar un patrón entonativo. Revista Internacional De Lingüística Iberoamericana, 3-2 (6), 137-150.

Wang, B., Xu, Y., y Ding, Q. (2018). Interactive Prosodic Marking of Focus, Boundary and Newness in Mandarin. Phonetica, 75 (1), 24-56. https://doi.org/10.1159/000453082

Xu, Y. (2015). Intonation in Chinese. En Sun, C. y Wang, W.S.-Y. (Eds.). The Oxford handbook of Chinese linguistics (pp. 490-502). Oxford University Press. 